\title{
Neonatal transports—risks and opportunities
}

\author{
Alf Meberg $^{1 *}$, Thor Willy Ruud Hansen ${ }^{2,3}$ \\ ${ }^{1}$ Department of Paediatrics, Vestfold Hospital Trust, Tønsberg, Norway; \\ ${ }^{2}$ Department of Neonatology, Women \& Children's Division, Oslo University Hospital HC-Rikshospitalet, Oslo, Norway; \\ ${ }^{3}$ Institute of Clinical Medicine, Faculty of Medicine, University of Oslo, Oslo, Norway. \\ Email: ${ }^{*}$ alfmeberg@yahoo.no
}

Received 22 September 2011; revised 30 October 2011; accepted 3 November 2011

\begin{abstract}
Aim: To assess the need for and quality of neonatal transports. Material and methods: Prospective observational study of consecutive transports from a level II neonatal unit. Results: 500 transports were undertaken 1982-2010 in 445 patients, representing $0.7 \%$ of liveborn infants $(n=61,450)$. Indications were congenital malformations in $223(45 \%)$, prematurity/respiratory distress syndrome (RDS) in 87 (17\%), and other conditions in 190 (38\%). For patients ventilated during transport $(n=121)$ mean $\mathrm{pCO}_{2}$ was improved at arrival, and for spontaneously breathing patients mean $\mathrm{pH}, \mathrm{pCO}_{2}$, and base excess $(p<0.05)$. After establishing a local respirator programme from 1989, transports for prematurity/RDS declined from 3.4 per 1000 live born infants in $1982-1988$ to 0.8 per 1000 in $1989-2010(p<0.0001)$, and night-time transports (departure between 22.00 pm - 06.00 am) declined from $24 / 119(20 \%)$ to $38 / 381$ $(10 \%)(p=0.003)$. Technical mishaps or severe clinical deterioration occurred in $16(3 \%)$ of the transports. Conclusions: Neonatal transport carries risks, but also an opportunity for further stabilization and improvement. A local respirator programme reduced the need for transfer of premature infants with RDS as well as for transports during night-time.
\end{abstract}

Keywords: Acidosis; Hypothermia; Newborn Infants; Transport

\section{INTRODUCTION}

In an unselected population of newborn infants $1 \%-2 \%$ are estimated to be in need of advanced care in a level III neonatal unit [1]. Postnatal transports of such patients from level II units may cause discontinuity in monitoring and treatment, with increased risk for deterioration $[2,3]$. A high-quality neonatal transport system thus is a key element in regionalized perinatal care programmes [4].
The aim of the present study was to assess the quality of 500 consecutive transports from a level II neonatal unit in infants born 1982-2010, as judged from clinical data, laboratory tests and technical mishaps. Our hypothesis was that the transit time was an opportunity for further stabilization with clinical and laboratory improvement, and that a local ventilator treatment programme (established 1989) would cause a decline in the need for transports, especially for preterm infants with respiratory distress syndome (RDS).

\section{MATERIAL AND METHODS}

\subsection{Population}

Vestfold Hospital serves a population of 220,000 inhabitants in the County of Vestfold, Norway. The hospital has the only delivery and neonatal unit in the county, where $90 \%$ of the pregnant women deliver their babies (about 2000 each year). The neonatal unit is a level II unit undertaking some level III tasks (such as short term ventilator treatment, established from 1989). In threatened preterm delivery before week 28 of gestation, and when severe fetal malformations have been diagnosed, the pregnant woman is transferred to the regional hospital for delivery. Steroid treatment to promote fetal lung function in preterm delivery was introduced 1991, and surfactant treatment for severe RDS from 1992.

During the 29-year period 1982-2010 data from 500 consecutive transports from the neonatal unit were recorded prospectively (clinical and laboratory data, technical mishaps). The study was approved by the regional committee for medical research ethics.

\subsection{Transport System}

The vast majority of transports were by ground vehicle (ambulance) to the regional hospital, a distance of 100 $\mathrm{km}$. A Dräger Medical transport incubator 5400 with a Babylog 2000 respirator and monitoring equipment including electrocardiogram, respirogram, continuous rectal temperature sensor and pulse oximeter was used. 
Blood samples and $\mathrm{X}$-ray pictures were taken at departure for final stabilizing procedures at the discretion of the attending pediatrician, and at arrival, especially in patients recognised as unstable or potentially unstable.

Transports were organized and carried out by personell from the local neonatal unit after necessary diagnostic evaluation and stabilizion. Depending on the clinical condition, transports were attended by a paediatrician (unstable, sick patients) or neonatal nurse (stable patients). The organizing, equipment (except for pulse oximetry introduced 1986) and guidelines for transports remained the same during the whole period. Nasal continuous positive airway pressure (CPAP) was not used.

\subsection{Statistics}

Statistical calculations were done by paired two group t-test, Fisher's exact test, and chi-sqare-test. The computer programme StatView II, Abacus Concepts, Berkely, USA was used for the analyses. A $p$-value $<0.05$ was considered statistically significant.

\section{RESULTS}

\subsection{Need for Transports}

During the 29-year period 1982-2010 61,450 infants were born alive at the hospital. Of these $445(0.7 \%)$ were, following admission to the neonatal unit, transferred to another hospital. 404 (91\%) were transported to the regional/national hospital for specialized care, and the remaining 41 transferred to their home hospital in other provinces in Norway or abroad. 37 patients were transported more than once (range 2 - 4), accounting for a total of 55 retransports. Thus, a total of 500 transports were carried out, $466(93 \%)$ by ambulance, 22 by taxi (4\%), $9(2 \%)$ by aeroplane, and $3(0.6 \%)$ by helicopter.

184 transports (37\%) occurred during the first 24 hours after birth, and an additional 120 (24\%) later on the first week of life. Figure 1 shows the time of day of departure. Most of the transports departed in the morning, while $62(12 \%)$ left the hospital during the nighttime (between $22.00 \mathrm{pm}$ and $06.00 \mathrm{am}$ ). The percentage of night-time transports, after establishing a local ventilator programme 1989 , declined from $24 / 119(20 \%)$ for infants born $1982-1988$ to $38 / 381$ (10\%) for infants born $1989-2010(p=0.003)$.

Table 1 shows the number of transports for malformations, prematurity/RDS and other conditions. The incidence of transports was unchanged. 119 transports $(0.8 \%)$ in 14,271 live born infants were undertaken 1982-88 compared to $381(0.8 \%)$ in 47179 infants born in 1989$2010(p=0.76)$. Transports of infants with congenital malformations were done in 48/14,271 (3.4 per 1000) and 175/47 179 (3.7 per 1000) respectively in the two periods $(p=0.55)$. There was a highly significant reduc-

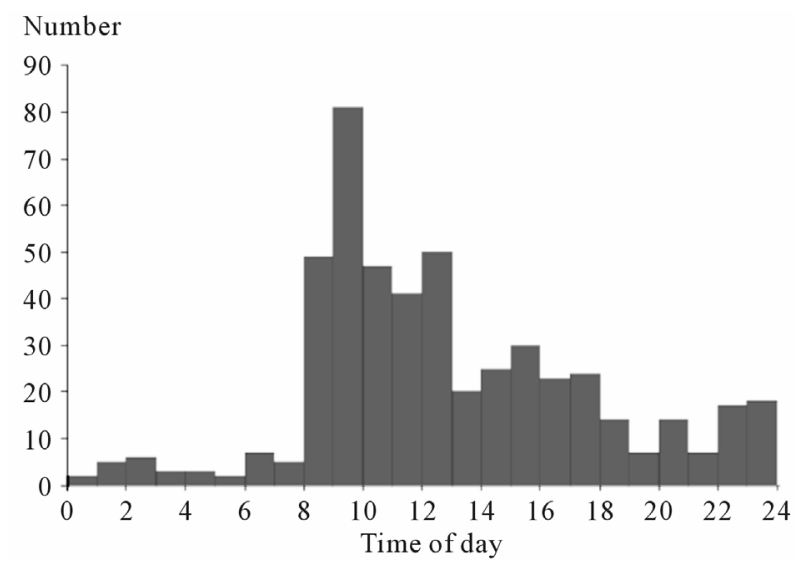

Figure 1. Time for departure from the neonatal unit in 500 transports.

tion in transfer of preterm infants with RDS, from 48/14 271 (3.4 per 1000 live born) $1982-1988$ to $39 / 47179$ $(0.8$ per 1000) born 1989-2010 $(p<0.0001)$. For the other conditions respectively 23/14 271 (1.6 per 1000) and $167 / 47,179$ (3.5 per 1000) were transported $(p=$ 0.0003 ). This increase was partly caused by more patients belonging to other provinces who needed transfer to their home hospitals after birth and initial care in our hospital, respectively 4/14 271 (0.3 per 1000) 1982-88 and 37/47,179 (0.8 per 1000) 1989-2010 ( $p=0.04)$. Retransports to the regional hospital also increased significantly from $3 / 14,271(0.2$ per 1000$)$ to $52 / 47,179(1.1$ per 1000) $(p=0.001)$. In 121 transports $(24 \%)$ the patient was mechanically ventilated.

\subsection{Temperature and Laboratory Tests}

Table 2 shows body temperature and laboratory values before departure and at arrival where paired values were available. No significant change in mean body temperature occurred, while blood glucose increased and hemoglobin concentration decreased significantly $(p<0.05)$. For the acid-base parameters significant changes occurred for mean $\mathrm{pH}, \mathrm{pCO}_{2}$ and base excess. In patients on ventilator during transport $(n=121) \mathrm{pH}$ was $7.26 \pm$ 0.17 (mean $\pm \mathrm{SD}$ ) and $7.29 \pm 0.16(p=0.12), \mathrm{pCO}_{2} 7.6$ $\pm 3.5 \mathrm{kPa}$ and $6.9 \pm 3.5 \mathrm{kPa}(p=0.01)$, and $\mathrm{BE}-2.6 \pm$ $6.9 \mathrm{mmol} / \mathrm{l}$ and $-3.3 \pm 6.7 \mathrm{mmol} / 1(p=0.26)$ respectively at departure and arrival. The corresponding values in patients breathing spontaneously during transport were $\mathrm{pH} 7.34 \pm 0.08$ and $7.36 \pm 0.08(p=0.006), \mathrm{pCO}_{2}$ $6.3 \pm 1.4 \mathrm{kPa}$ and $5.9 \pm 1.3 \mathrm{kPa}(p=0.0001)$, and $\mathrm{BE}$ $-2.3 \pm 4.5 \mathrm{mmol} / \mathrm{l}$ and $-0.8 \pm 5.0 \mathrm{mmol} / \mathrm{l}(p=0.046)$. In patients with critical heart defects given prostaglandin $\mathrm{E}_{1}$ (PGE) infusion during transport $(n=30) \mathrm{pH}$ was $7.29 \pm$ 0.13 and $7.34 \pm 0.10(p=0.05), \mathrm{pCO}_{2} 7.1 \pm 2.3 \mathrm{kPa}$ and $5.6 \pm 1.3 \mathrm{kPa}(p=0.002)$, and $\mathrm{BE}-3.8 \pm 5.0 \mathrm{mmol} / \mathrm{l}$ and $-3.2 \pm 4.1 \mathrm{mmol} / \mathrm{l}(p=0.68)$ respectively at departure 
Table 1. Indications for 500 consecutive transports 1982-2010.

\begin{tabular}{|c|c|c|c|c|c|c|}
\hline & \multicolumn{2}{|c|}{$1982-1988$} & \multicolumn{2}{|c|}{$1989-2010$} & \multicolumn{2}{|c|}{ Total } \\
\hline & $n$ & $\%$ & $n$ & $\%$ & $n$ & $\%$ \\
\hline Malformations & 48 & 40 & 175 & 46 & 223 & 45 \\
\hline - heart & 22 & & 63 & & 85 & \\
\hline - gastrointestinal tract & 8 & & 64 & & 72 & \\
\hline - central nervous system & 3 & & 16 & & 19 & \\
\hline - other & 15 & & 32 & & 47 & \\
\hline Prematurity/RDS & 48 & 40 & $39^{\mathrm{a}}$ & 10 & 87 & 17 \\
\hline Miscellaneous & 23 & 19 & $167^{\mathrm{a}}$ & 44 & 190 & 38 \\
\hline Total & 119 & 100 & 381 & 100 & 500 & 100 \\
\hline
\end{tabular}

${ }^{\mathrm{a}} p<0.05$; statistically significant difference from 1982-1988; RDS = respiratory disress syndrome.

Table 2. Body temperature and laboratory tests before departure and at arrival.

\begin{tabular}{|c|c|c|c|c|c|c|}
\hline & \multirow{2}{*}{$n$} & \multicolumn{2}{|c|}{ Before departure } & \multicolumn{2}{|c|}{ At arrival } & \multirow{2}{*}{ p-value } \\
\hline & & Mean & Range & Mean & Range & \\
\hline$T_{p}\left({ }^{\circ} \mathrm{C}\right)$ & 293 & 36.9 & $33.5-38.5$ & 36.9 & $34-39.7$ & 0.769 \\
\hline Glucose (mmol/l) & 226 & 4.6 & $0.3-16.7$ & 5.1 & $0.5-19.9$ & 0.006 \\
\hline Hemoglobin $(\mathrm{g} / 100 \mathrm{ml})^{\mathrm{a}}$ & 188 & 18.1 & $11-26.2$ & 17.1 & $10.3-27.1$ & 0.0001 \\
\hline $\mathrm{pH}$ & 310 & 7.31 & $6.66-7.58$ & 7.33 & $6.74-7.63$ & 0.005 \\
\hline $\mathrm{pCO}_{2}$ & 303 & 6.7 & $2-20.3$ & 6.2 & $2.7-19.2$ & 0.0001 \\
\hline Base excess (mmol/l) & 309 & -1.2 & $-24.4-20$ & -1.7 & $-25-19.1$ & 0.038 \\
\hline
\end{tabular}

${ }^{\mathrm{a}}$ Transport before 72 hours after birth.

and arrival.

Figure 2 shows the number of infants with extreme values before departure and at arrival. Although there appeared to be a trend towards more patients with hypoand hyperthermia, hyperglychemia, anemia (only cases transported $<72$ hours of age were included to minimize the interference from the physiological decline in hemogloblin concentration), alkalosis, hypocapnea, and major base deficit at arrival, the numbers were not significantly different from the numbers with extreme values at departure $(p>0.05)$. Some patients with extreme values at departure also had extreme values at arrival. Two severely asphyxiated infants were intentionally hypothermic both at departure and arrival. Ten out of 18 patients $(56 \%)$ with body temperature $<36^{\circ} \mathrm{C}$ at arrival had low birth weight $(<2500 \mathrm{~g})$. Of 14 patients with severe acidosis $(\mathrm{pH}<7.10)$ at arrival five were transported for prematurity/RDS, three for persistent pulmonary hypertension, two for critical heart defects, and one each for group B streptococcal septicemia, diaphragmatic hernia, asphyxia and Potter syndrome.

\subsection{Technical Mishaps-Clinical Complications}

In 16 transports $(3 \%)$ severe technical failure or clinical complications were recorded. Accidental extubation, tube dislocation into the right main bronchus or tube dislocation from the connector occurred in eight patients, $7 \%$ of the patients who were ventilated. In two patients umbilical catheter complications occurred (bleeding because of catheter dislocation). In one transport the respirator failed, in one the oxygen supply ran out, and in one the ambulance broke down. One case developed pneumothorax (mechanically ventilated during transport) and in two spontaneously breathing infants severe apnoea requiring manual mask ventilation occurred.

\subsection{Mortality}

No infant died during transport, however, 14 died within 24 hours after arrival, accounting for a transport related mortality of $3 \%$. Six of these had letal malformations. A total of 58 infants (13\%) died before discharge from the regional hospital. Mortality declined from 27/116 infants $(23 \%)$ transported $1982-1988$ to $31 / 329(9 \%)$ transported $1989-2010(p=0.0001)$.

\section{DISCUSSION}

\subsection{Need and Time for Transports}

Of all live born infants $0.7 \%$ were transported to another 


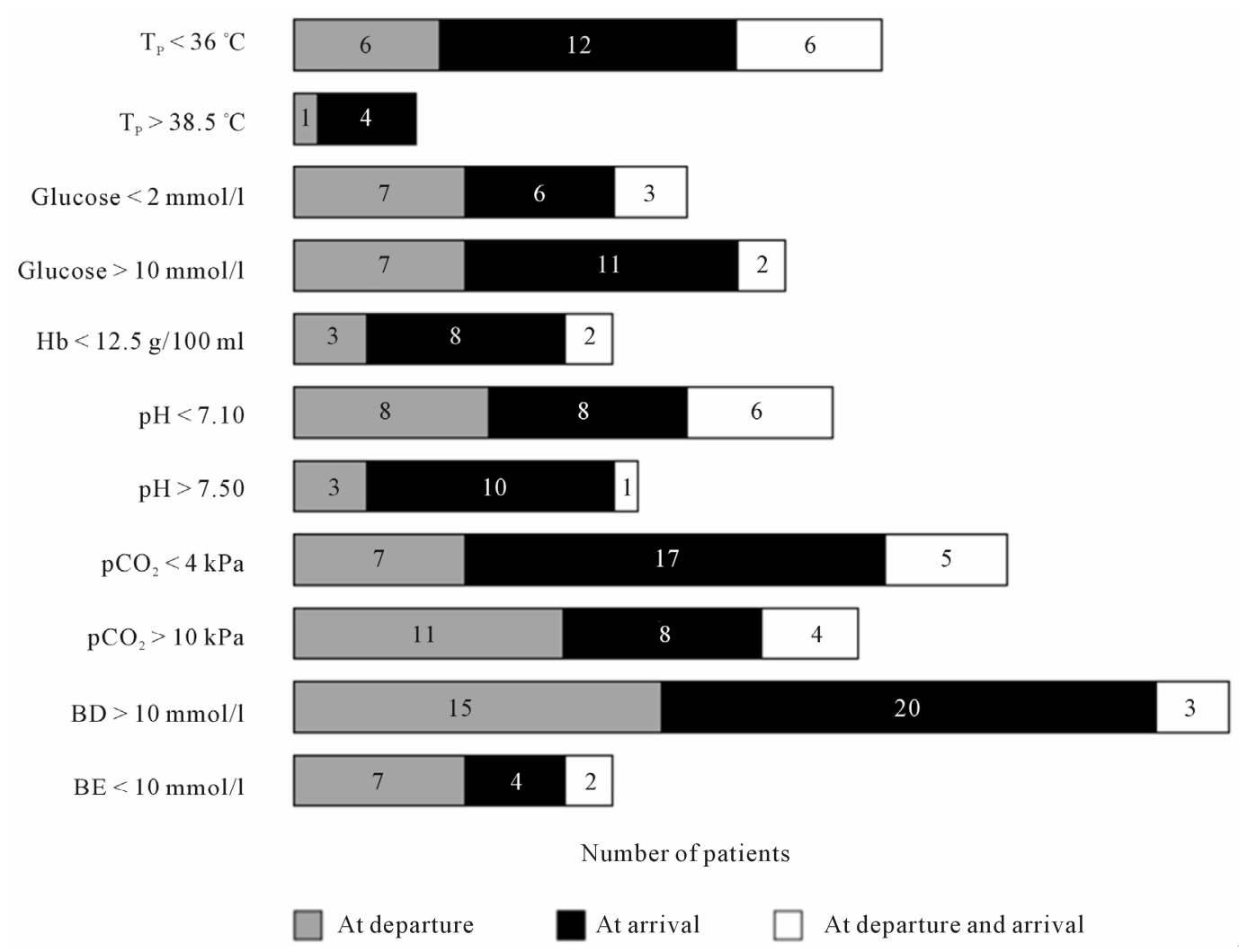

Figure 2. Number of infants with extreme values for body temperature, blood glucose, hemoglobin concentration (transports before 72 hours of age) and acid-base values before departure and at arrival.

hospital, of whom more than $90 \%$ to a regional hospital for advanced diagnostic procedures and therapeutic interventions. If in utero transports from the population are added, $1 \%$ of newborn infants were in need of treatment at the regional hospital (A Meberg, upublished data). This is in accordance with estimated needs for level III care in an unselected population of newborns [1]. However, the need for postnatal transports from level II neonatal units may vary according to local resources (ability to undertake selected level III tasks) and the quality of obstetric programmes to select high-risk pregnancies for ante natal transfer (maternal disease, fetal disease or malformations).

Most of the transfers occurred soon after birth, more than $1 / 3$ during the first 24 hours and $2 / 3$ during the first week. Infants with congenital malformations constituted the largest group. Although antenatal detection of such conditions has improved in recent years, with possibility for in utero transfer, the impact on postnatal transports was not significant. A substantial percentage of severe congenital malformations are still diagnosed postnatally. For preterm infants with RDS, however, a significant decline in transfer needs occurred after establishing a local ventilator treatment programme. Prenatal steroid treatment and surfactant in severe RDS most probably also have contributed to this [5]. At the same time the demand for night-time transports was halved. A local respirator programme provides opportunities for better stabilization of the patient, and allocation to day-time transportation, when resources for transfer are more optimal.

The increasing number of infants transferred to their home hospitals may be an indicator for more cooperation between health regions. An increase of infants in need of more than one transport indicates a more dynamic interaction between the regional and the subregional hospital.

\subsection{Clinical and Laboratory Results}

The present study emphasizes the risk for clinical and laboratory deterioration of infants undergoing transport (Figure 2). A higher blood glucose level at arrival may be an indicator of stress, and decline in hemoglobin concentration may represent fluid overload or blood loss. On the other hand, significant normalization of acid-base parameters shows that transferral may also be an opportunity for further stabilization and improvement. This was well demonstrated in the subgroup of infants with critical heart defects who received PGE infusion. Improved clinical condition of newborns at the end of transfer has also been found in other studies [6,7]. 
Most of the patients with hypothermia (body temperature $<36^{\circ} \mathrm{C}$ ) at arrival were low birthweight infants, caused by insufficient temperature regulation and increased heat loss because of a large body surface to weight ratio in these patients. Our experiences are in agreement with other studies [8]. Temperature monitoring, best performed continuously with a rectal probe, thus is an important procedure in neonatal transports.

There was a trend for more infants with extreme values for body temperature, blood glucose, hemoglobin, and acid-base parameters at arrival (Figure 2). It is a matter of concern that some patients with extreme values at departure also had extreme values at arrival. This suggests insufficient stabilization, or that the condition could not be stabilized. When a specialized retrieval team carries out the transport, the quality of transports has been shown to be improved compared to local ad hoc teams $[9,10]$. A special challenge is pulmonary hypertension, causing severe hypoxia and metabolic acidosis. The risk for death or sequelae is high in these patients, who may need ventilation with nitric oxide to reduce pulmonary vascular resistance [11] or extractorporal membrane oxygenation to ensure oxygenation [12]. Few hospitals have the possibility to provide such treatment during transport, and will need help from sentralized transport systems with advanced technology.

\subsection{Technical Mishaps}

Technical errors occurred in some of the transports. This emphasizes the importance of a high-quality work with focus on technical details, especially in the pretransport stabilization period. Proper fixation of the tracheal tube, $\mathrm{X}$-ray control of tube position and necessary correction before departure, sedation of active infants (e.g. when mechanically ventilated) are important points in order to avoid tube dislocation. The same principles apply for umbilical vessel catheters.

\subsection{Mortality}

The transport-related mortality (dead during the first 24 hours after arrival) was low (3\%), with nearly half dying from letal malformations. Better diagnostics could possibly have avoided some of these futile transports.

A considerable decline in mortality of transported infants occurred without contemporary increasing mortality in the referring hospital (A Meberg, unpublished data). The reason for this is multifactorial, reflecting progress of neonatal care. Better organization of transports, and better stabilization and treatment of the patients are important factors. An indicator for this may be the reduced percentage of night-time transports following improvements in the local intensive care programme. However, in spite of high quality postnatal transports, in utero transfer is, when possible, the better choice $[13$, 14].

\section{CONCLUSIONS}

Neonatal transport carries risks, but also an opportunity for further stabilization and improvement. A local respirator programme reduced the need for transfer of premature infants with RDS as well as for transports during night-time.

\section{ACKNOWLEDGEMENTS}

The study was supported by a grant from Vestfold Hospital Trust.

\section{REFERENCES}

[1] Neonatal Care in Norway (1990) Helsedirektoratets utredningsserie nr. 2/1990. The Norwegian Health Directorate, Oslo.

[2] Mohamed, M.A. and Aly, H. (2010) Transport of premature infants is associated with increased risk for intraventricular haemorrhage. Archives of Disease in Childhood Fetal Neonatal Edition, 95, F403-F407.

doi:10.1136/adc.2010.183236

[3] Lang, A., Brun, H., Kaaresen, P.I. and Klingenberg, C. (2007) A population based 10-year study of neonatal air transport in North Norway. Acta Paediatrica, 96, 995999. doi:10.1111/j.1651-2227.2007.00320.x

[4] Shenai, J.P., Major, C.W., Gaylord, M.S., Blake, W.W., Simmons, A., Oliver, S., et al. (1991) A successful decade of regionalized perinatal care in Tennessee: The neonatal experience. Journal of Perinatology, 11, 137143.

[5] Mildenhall, L.F.J., Pavuluri, N.N. and Bowman, E.D. (1999) Safety of synthetic surfactant use before preterm newborn transport. Journal of Paediatrics and Child Health, 35, 530-535.

doi:10.1046/j.1440-1754.1999.00414.x

[6] Hellström-Westas, L., Hanséus, K., Jögi, P. Lundström, N.R. and Svenningsen, N. (2001) Long-distance transports of newborn infants with congenital heart disease. Pediatric Cardiology, 22, 380-384.

[7] Mullane, D., Byrne, H., Clarke, T.A., Gorman, W., Griffin, E., Ramesh, K., et al. (2004) Neonatal transportation: The effects of a national neonatal transportation programme. Irish Journal of Medical Science, 173, 105108. doi:10.1007/BF02914569

[8] Holt, J. and Fagerli, I. (1999) Air transport of the sick newborn infant: Audit from a sparsely populated county in Norway. Acta Pcediatrica, 88, 66-71. doi:10.1111/j.1651-2227.1999.tb01271.x

[9] Yoder, B.A. (1992) Long distance perinatal transport. American Journal of Perinatology, 9, 75-79. doi:10.1055/s-2007-994675

[10] Arrøe, M., Steensgård, J. and Greisen, G. (2001) Emergency transport of new-born infants-Fetch or bring? Ugeskrift for Lager, 163, 1093-1097.

[11] Kinsella, J.P. (1995) Inhaled nitric oxide treatment for stabilization and emergency medical transport of critically ill newborns and infants. Pediatrics, 95, 773-776. 
[12] Heulitt, M.J., Taylor, B.J., Faulkner, S.C., Baker, L.L., Chipman, C.W., Harrell, J.H., et al. (1995) Inter-hospital transport of neonatal patients on extracorporeal membrane oxygenation: Mobile-ECMO. Pediatrics, 95, 562566.

[13] Modanlou, H.D., Dorchester, W.L., Freeman, R.K. and Rommal, C. (1980) Perinatal transport to a regional perinatal center in a metropolitan area: Maternal versus neonatal transport. American Journal of Obstetetrics and
Gynecology, 138, 1157-1164.

[14] Shlossman, P.A., Manley, J.S., Sciscione, A.C. and Colmorgen, G.H. (1997) An analysis of neonatal morbidity and mortality in maternal (in utero) and neonatal transports at 24-34 weeks' gestation. American Journal of Perinatology, 14, 449-456.

doi:10.1055/s-2007-994178 